\title{
Non-linear Nature of Positive Parental Sentiments in Analyzing the 1st Type of Correlative Errors
}

\author{
Mikhail Basimov \\ Doctor of psychological sciences, Professor \\ Department of labour psychology and special psychology \\ Russian State Social University (RSSU) \\ Moscow, Russia \\ basimov_@mail.ru \\ Elena Padurina \\ Ph.D. of Psychology \\ Associate Professor of Humanitarian Institute \\ Kurgan State University (KSU) \\ Kurgan, Russia \\ len04ka.06@mail.ru
}

\begin{abstract}
Based on a study of positive parental sentiments we have treated of the issue of ignoring the simplest non-linear relations (dependencies with a maximum and a minimum in the first place) when even "significant" linear correlations are missing, which results in system errors (1st type of errors by the author's terminology). The article supplies samples of dependencies (a total of 22) with linear correlations close to zero, which traditionally are not singled out as worth of note for describing and interpreting. In fact, there is, for these couples of variables, a really strong simplest non-linear dependency which completely changes the phenomenon under consideration, opening at the same time new relations supplying information for description. The article graphically shows the real amount of ignored results (invisible in the correlative analysis) that can arise in the course of any investigation when the focus is on linear correlations, plunging into linear models in interpreting the results while ignoring the real non-linear nature of psychological phenomena.
\end{abstract}

Keywords - parenthood, positive feelings, non-linearity, the spouse, the child, comparative weightiness, dependencies.

\section{INTRODUCTION}

Today, the science "on the one hand investigates at the philosophical and methodological level the ideas of synergy [9], as applied to social sciences (sciences about a man), and, on the other hand, excepting individual studies, proposes through psychologists relying on their search results, certain interpretations of exclusively linear relations [10] and interpretations of exclusively linear models." The non-linear nature of psychological (sociological) data is not a relevant issue for most of the researchers [5]. Here it should be noted that the author's method alone has made it possible to determine the non-linearity of psychological and social phenomena in numerous investigations.

The study of non-linear relations by the author's method [1] was tested in different psychological studies presenting diverse areas of the psychological science, such as the psychology of preschool children and teenagers, the political psychology, the ethno-psychology, the occupational psychology [3], the psychology of trust, the psychology of Personality [4], the psychology of stress, the psychology of parenthood [14], the psychology of learning, the measuring of the value-relations of a person "Me and Others", the study of the family upbringing as a factor that shapes the child's meaningful spheres [7, 8], and the study of the dynamics of motivational and semantic formations in a student's personality, etc.

Let us consider an example (a dissertation by E.A.Padurina [13] from which it's clear that ignoring the complex nature of psychology in studying the parental matters and an attempt to present the investigation results as a mechanistic outcome brings about not only a large loss of info (represented by simplest non-linear dependencies) but also a large number of system errors in construing the results. Let us consider the general structure of investigation results dedicated to parents' positive sentiments and their impact on a pre-school child's self-evaluation in terms of non-linear psychology.

The investigation has used the following diagnostic tools: 
1) a questionnaire for "studying the emotional aspect of child-to-parent relationships" as presented by E.I. Zakharova;

2) the method "The parents' positive sentiments" by E.A. Padurina,

3) questionnaire "Parent-to-child relationship" by I.M. Markovskaya;

4) "The Sentiments' Profile" methods by L.V. Kulikova;

5) “A Person's Emotional Attitudes" methods by L.V. Kulikova;

6) "The Ladder" modified method by G.V. Shchur.

For addressing the issue of relations the following parameters were chosen:

Age (X01)

Questionnaire "Parent-to-child interaction" by I.M.Markovskaya: Exactingness - non-exactingness (X02); Lenience - strictness (X03); Autonomy - supervision (X04); Emotional remoteness - closeness (X05); Rejection acceptance (X06); Lack of cooperation - cooperation (X07); Anxiety over the child (X08); Inconsistency - consistency (X09); Upbringing confrontation in the family (X10); Satisfaction with relationship with the child (X11) [12]

The method "Positive parental sentiments" by E.A.Padurina: "The emotional component of positive parental sentiments (X12); A cognitive component of positive parental sentiments (X13); Behavioral component of positive parental sentiments (X14); Positive sentiments about oneself as a parent (X15); Positive sentiments about parenthood (X16); Positive sentiments about a child based on his dignity and achievements (X17); Positive sentiments about a child based on an unconditional acceptance (X18); Parental love (X19); Positive sentiments about the spouse as a parent (X20)" [13].

Questionnaire for studying the emotional aspect of a child-to-parent interaction by E.I. Zakharova: An ability to perceive a child's condition (X21); The understanding of the causes of such a condition (X22); The ability for empathy (X23); Sentiments emerging in a mother while interacting with her child (X24); Unconditional acceptance (X25); Attitude to oneself as a parent (X26); The prevailing emotional background of interaction (X27); Desire for a physical contact (X28); Rendering emotional support (X29); Orientation to the child's condition in building a relationship (X30); An ability to impact a child's condition (X31) [16].

Method "A sentimental profile in a relationship" by L.V. Kulikov: Hedonistic sentiments (X32); Asthenic sentiments (X33); Melancholic sentiments (X34); Sentiments that bring closer (X35); Sentiments that draw apart (X36); Preceding developments (X37) [11].

Method "Emotional direction of a person" by B.I. Dodonov: Altruistic emotional orientation (X38); Communicative emotional orientation (X39); Gloric emotional orientation (X40); Praxical emotional orientation (X41); Romantic emotional orientation (X42); Gnostic emotional orientation (X43); Aesthetic emotional orientation (X44); Hedonistic emotional orientation (X45); Acquisitive emotional orientation (X46); Pugnatic emotional orientation (X47) [6].

Modified version of the "Ladder" method by G.V. Shchur: General self-estimation of a child (X48); Particular self-estimation of a child (prognosticated estimation of a parent) (X49); A parent's estimation of a child (X50) [15].

In the article we consider the results of one of the three resolved tasks (for triads, quarters, and quinter-independent variable) of determining the relations between the variables under study, i.e. the tasks involving a quarter-independent variable.

Based on the author's method of multiple comparison, a new approach was elaborated for studying variously-shaped statistical dependencies. "This method employs a generalized version of the multiple comparison method for quantile splitting (quarters, quinters) of data by each parameter being measured, so that there is no need to preliminarily propose a hypothesis about the shape of dependence. As a result, the strength and shape of dependence are determined while linear dependencies are established as a specific particular case. The proposed approach not only enables the simultaneous tracking of various types of non-linear dependencies, but also makes it possible to determine for which intervals of parameter values those dependencies are observed. This allows a more precise interpretation of results" [1].

\section{RESUlTS}

"Let's show the identifications, which will be used in the offered tables:

SV - factor of the connection strength determining the dependence of the parameter of the number $\mathrm{N} 2$ (parameter) from the parameter for the number N1(quarters);

$\mathbf{S V}^{\prime}$ - factor of the connection strength determining reverse (in relation to $\mathrm{SV}$ ) dependence of the parameter with number N1 (quarters) from the parameter with number N2 (parameter);

$\mathbf{R}$ - the coefficient of linear correlation between parameters with numbers N1 (quarters) and N2 (parameter);

$\mathbf{N 1}$ (quarters) - number of the parameter, for which is made splitting on quarters;

$\mathbf{N 2}$ (parameters) - number of the parameter, which values are determined for the distinguished quarter of the parameter with number N1.” [2]

The first selection of dependencies (Table 1) contains the strongest simplest non-linear dependencies with a connection strength factor SV>0.7, which can be accepted as being of zero value without interest in terms of investigation and even not included in the category of "significant" correlations. They 
are characterized by values from 0 to 0.16 . The value 0.16 is the benchmark after which (for a selection of 140) the community of psychologists considers the correlation significant and worth of attention in interpreting their results in the framework of traditional linear models. In this case, the psychologists often ignore (see the numerous articles) the differences in the value of the correlation factor: $0.16,0.6$ or even 1 are for them "a significant value", which they regard as sufficient and satisfactory.

Thus, we find 11 strong simplest non-linear relations, which in the framework of correlative analysis would remain just unnoticed since they are actually close to zero.

Further, let us present these 11 dependencies (Figure 111) without description and interpretation in order to graphically show in this article the amount of pseudoscientific results that can emerge in any investigation when the focus is exclusively on linear correlations and, while delving into linear models for interpreting the results, simultaneously ignoring the actual non-linear nature of psychology, dependencies with a maximum or a minimum in the first place.

TABLE I $\quad$ INTERVALS OF RELATION COEFFICIENTS: $0<\operatorname{ABS}(\mathrm{R})<=0.16 \quad 0.7<\mathrm{SV}<=2$

\begin{tabular}{|c|c|c|c|c|c|}
\hline & SV & SV $^{\prime}$ & $\mathbf{R}$ & quarters & Parameter \\
\hline 1 & $\mathbf{0 . 7 2}$ & 0.10 & $\mathbf{0 . 0 9}$ & X02 & X49 \\
\hline 2 & $\mathbf{0 . 7 4}$ & 0.35 & $\mathbf{0 . 0 0}$ & X14 & X30 \\
\hline 3 & $\mathbf{0 . 8 8}$ & 0.33 & $\mathbf{0 . 1 2}$ & X21 & X38 \\
\hline 4 & $\mathbf{0 . 8 7}$ & 0.12 & $\mathbf{- 0 . 0 3}$ & X22 & X02 \\
\hline 5 & $\mathbf{0 . 9 7}$ & 0.19 & $\mathbf{0 . 1 1}$ & X37 & X04 \\
\hline 6 & $\mathbf{0 . 8 7}$ & 0.07 & $\mathbf{- 0 . 0 7}$ & X40 & X18 \\
\hline 7 & $\mathbf{0 . 7 4}$ & 0.14 & $\mathbf{0 . 1 1}$ & X42 & X41 \\
\hline 8 & $\mathbf{0 . 8 3}$ & 0.35 & $\mathbf{- 0 . 0 5}$ & X43 & X16 \\
\hline 9 & $\mathbf{0 . 9 0}$ & 0.22 & $\mathbf{0 . 0 6}$ & X43 & X17 \\
\hline 10 & $\mathbf{0 . 8 3}$ & 0.03 & $\mathbf{- 0 . 0 8}$ & X47 & X33 \\
\hline 11 & $\mathbf{0 . 9 0}$ & 0.22 & $\mathbf{0 . 0 5}$ & X48 & X40 \\
\hline
\end{tabular}

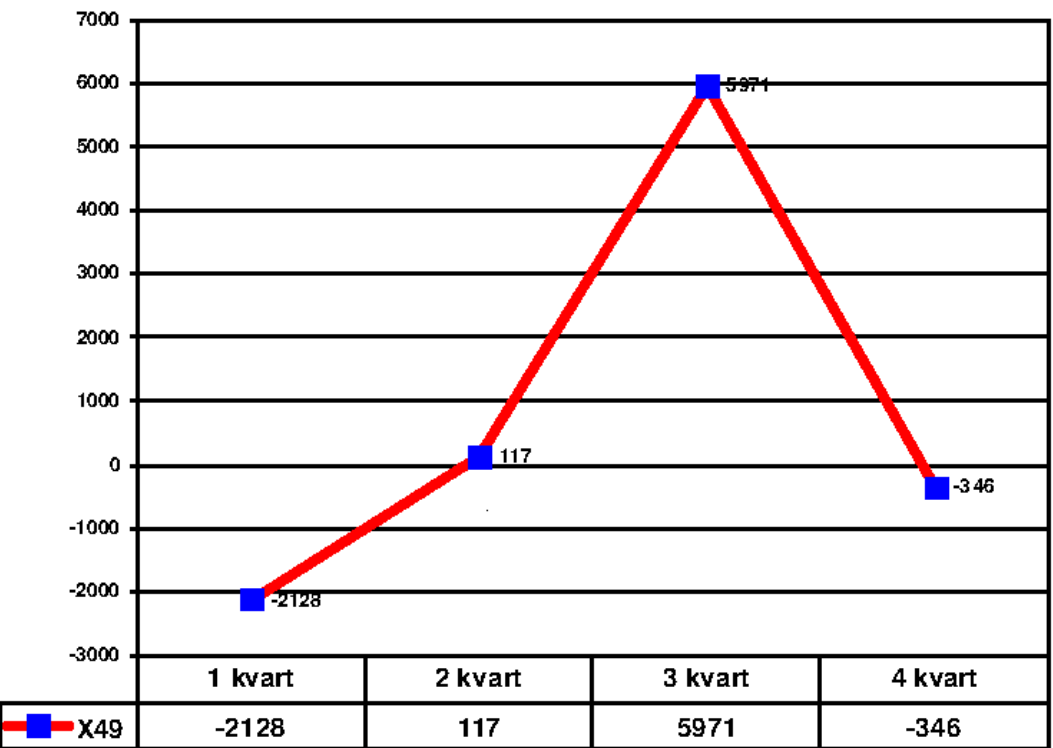

Figure 1. Dependence of the parameter "Particular self-estimation of a child (prognosticated estimation of a parent)" (X49) from the parameter "Exactingness - non-exactingness" (X02); 


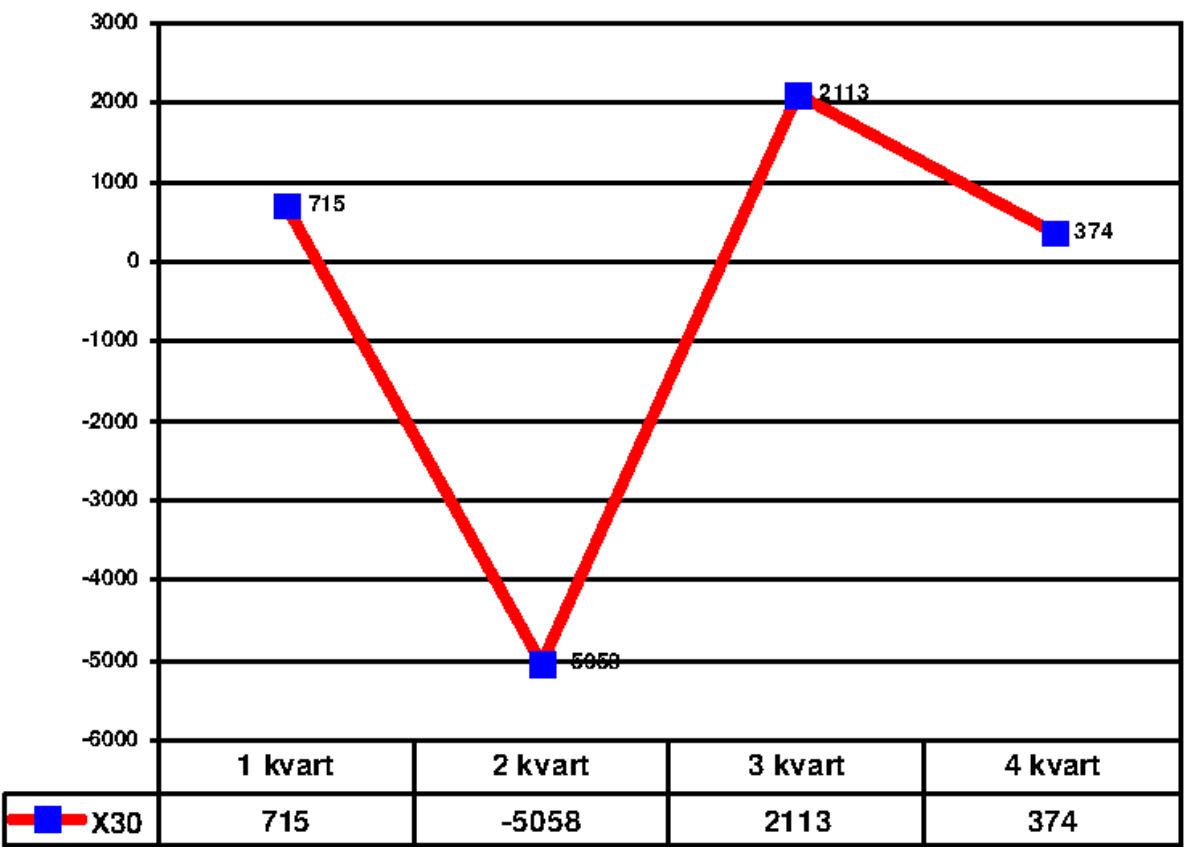

Figure 2. Dependence of the parameter "Orientation to the child's condition in building a relationship" (X30) from the parameter "Behavioral component of positive parental sentiments" (X14).

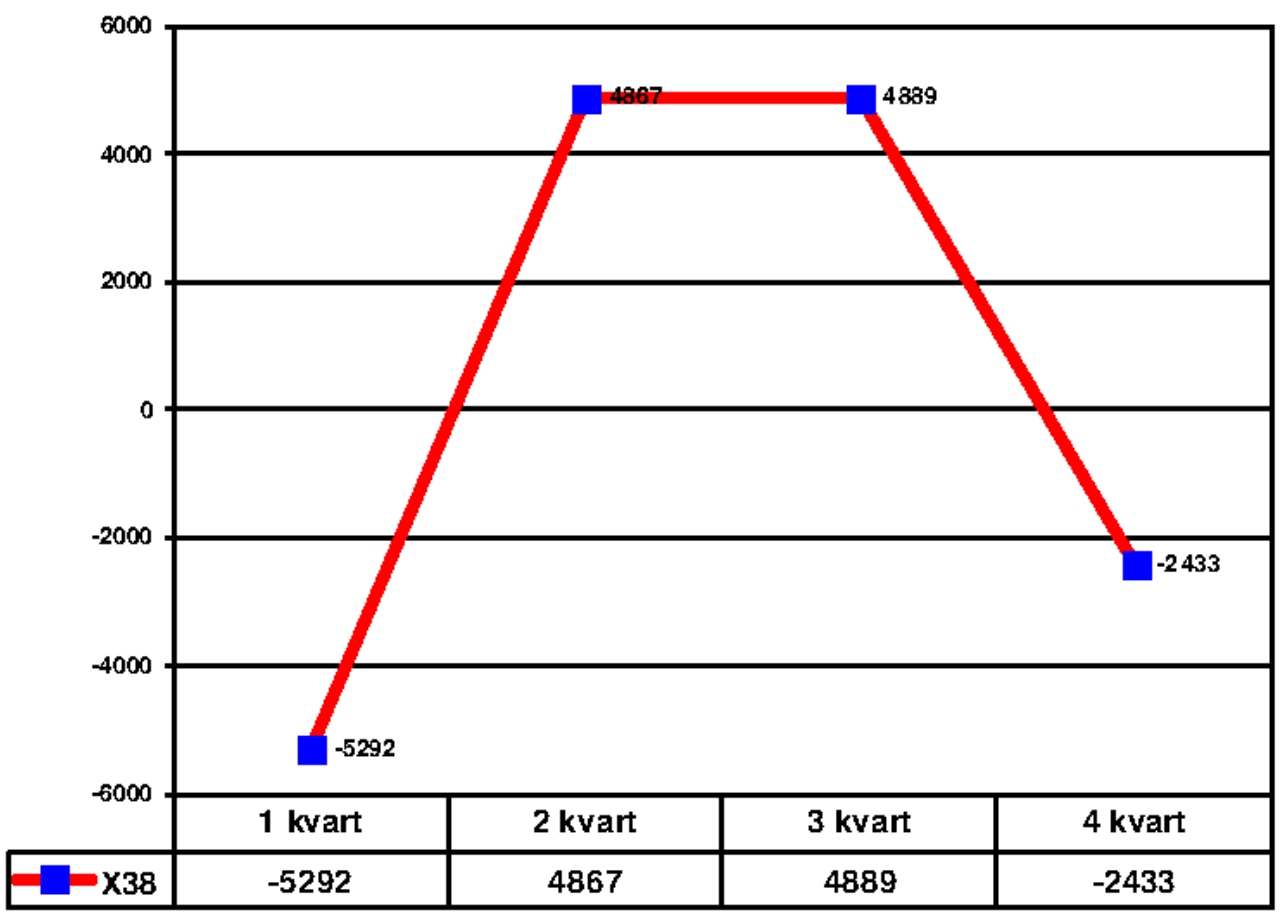

Figure 3. Dependence of the parameter "Altruistic emotional orientation" (X38) from the parameter "An ability to perceive a child's condition" (X21); 


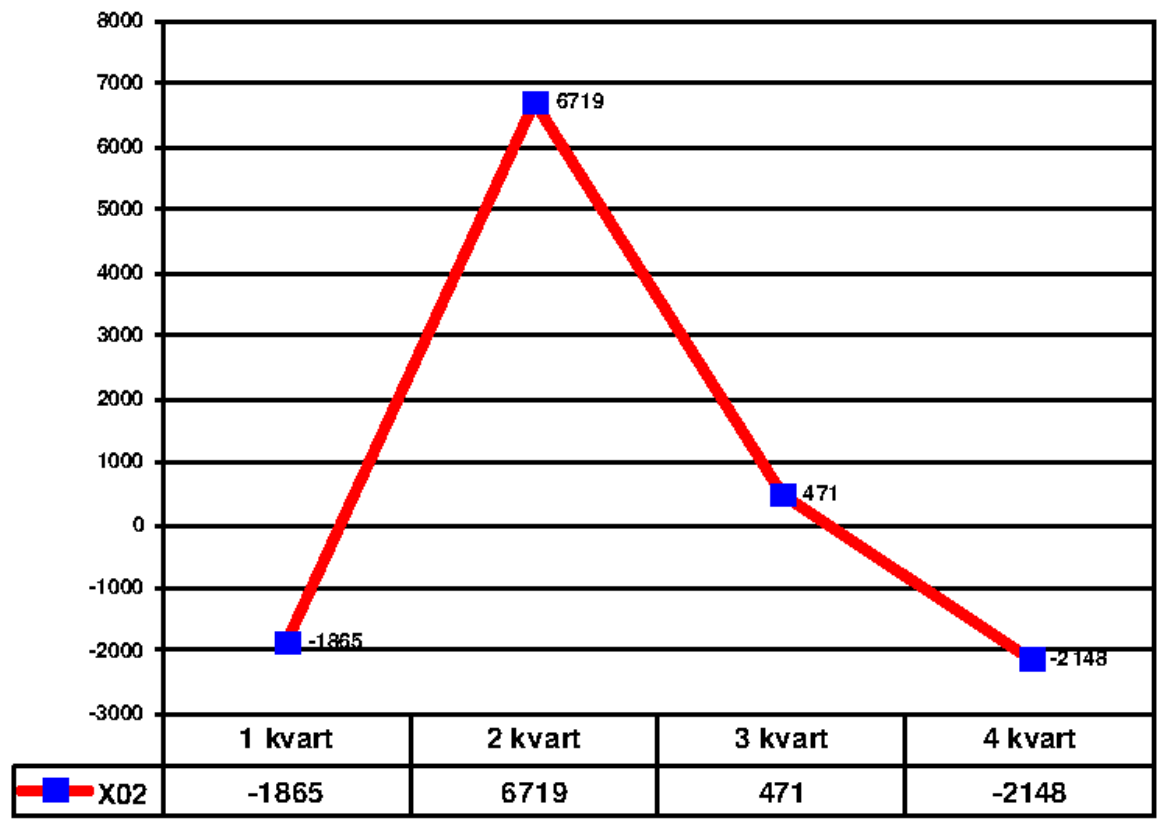

Figure 4. Dependence of the parameter "Exactingness - non-exactingness" (X02) from the parameter "The understanding of the causes of such a condition" (X22).

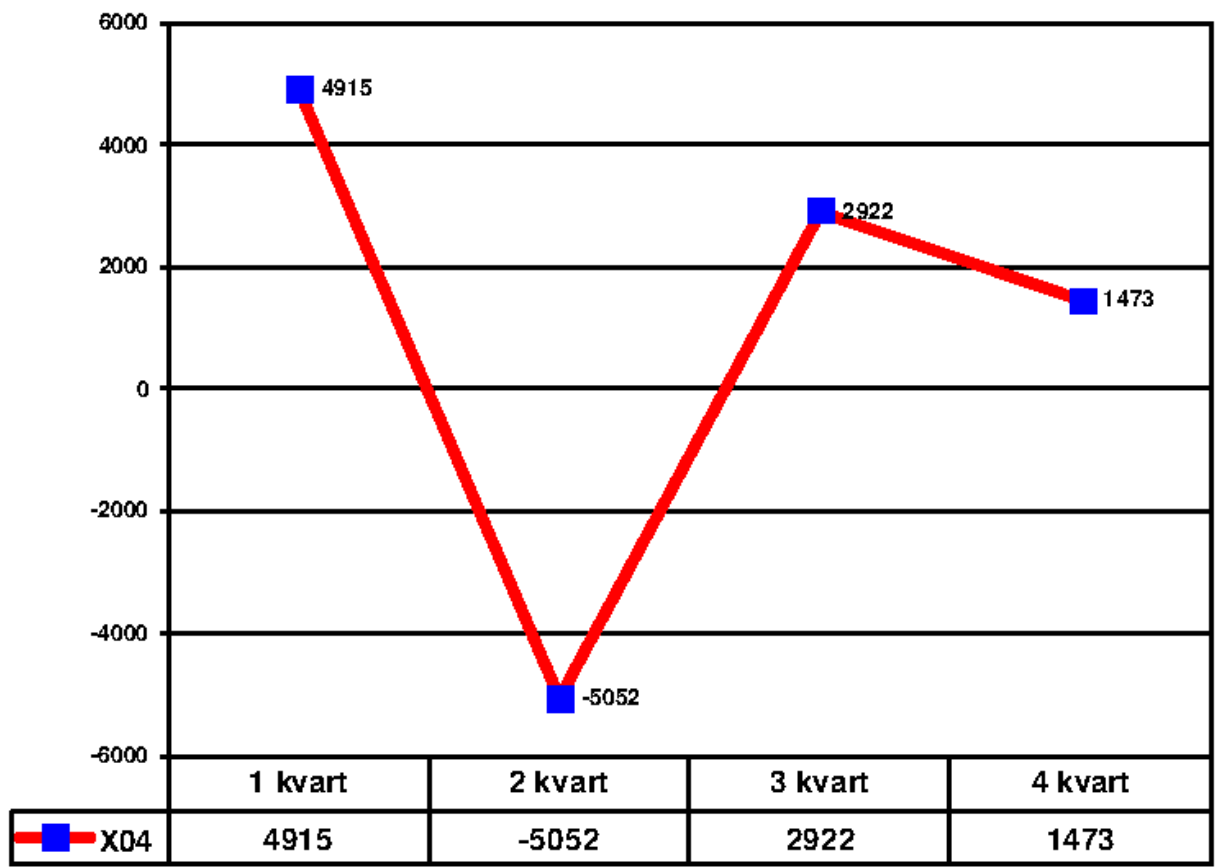

Figure 5. Dependence of the parameter "Autonomy - supervision" (X04) from the parameter "Preceding developments" (X37); 


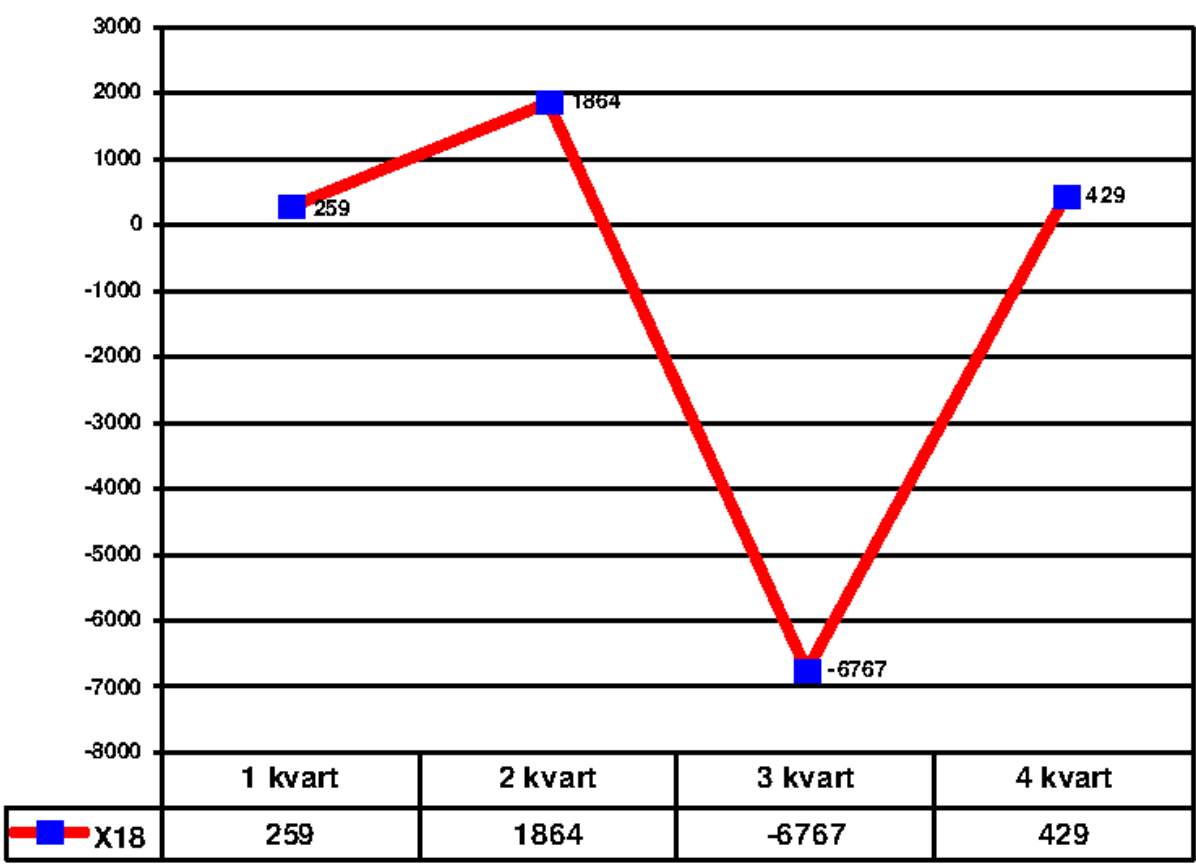

Figure 6. Dependence of the parameter "Positive sentiments about a child based on an unconditional acceptance" (X18) from the parameter "Gloric emotional orientation" (X40).

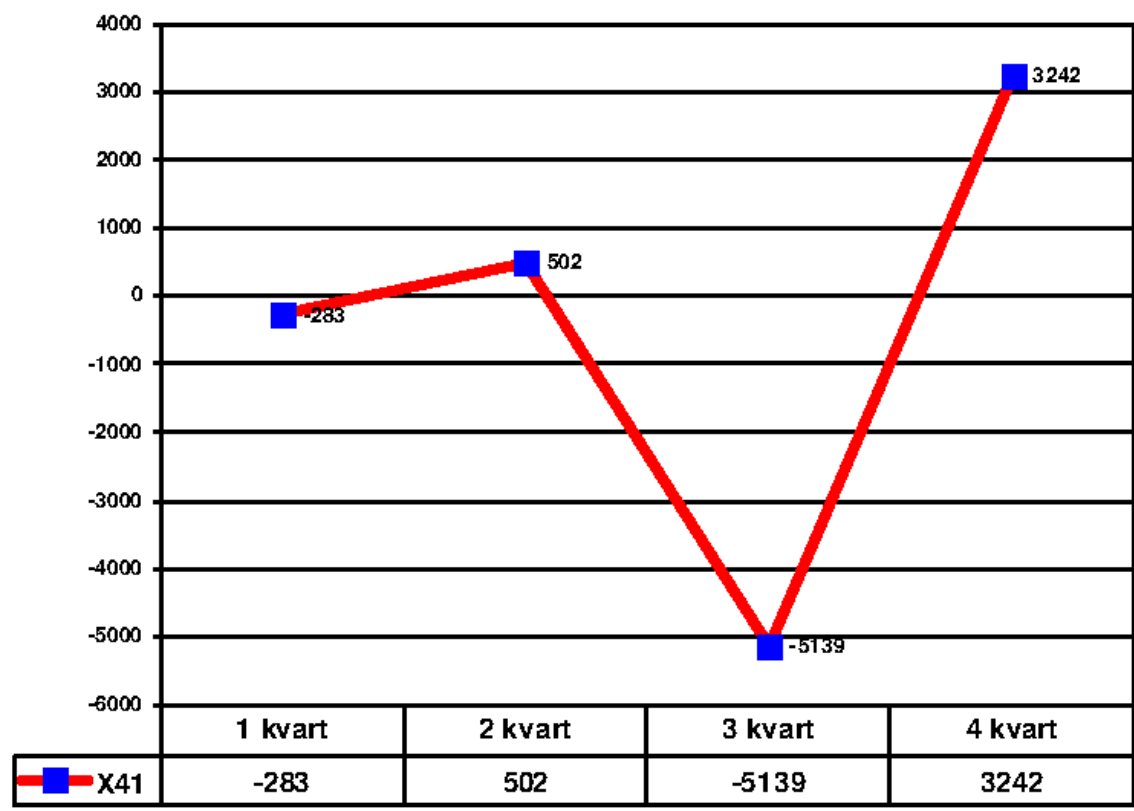

Figure 7. Dependence of the parameter "Praxical emotional orientation" (X41) from the parameter "Romantic emotional orientation" (X42); 


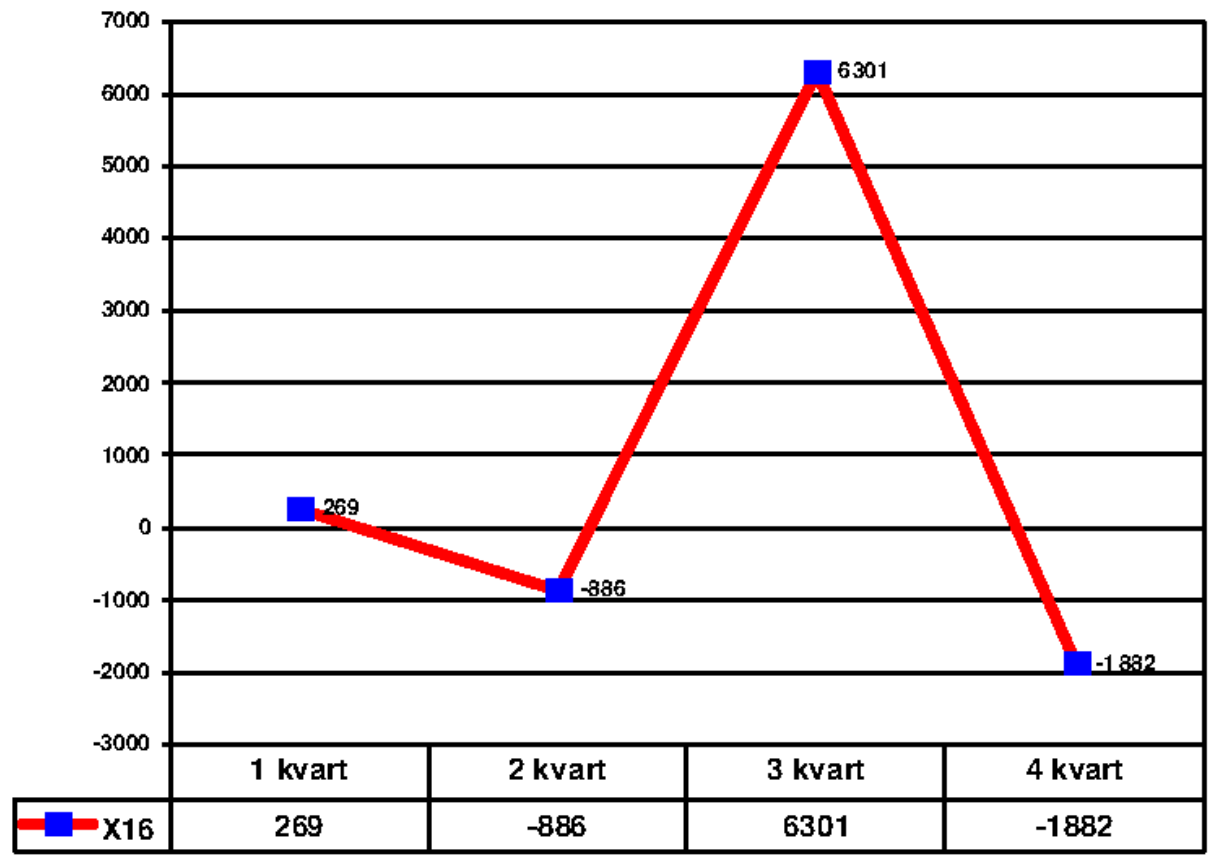

Figure 8. Dependence of the parameter "Positive sentiments about parenthood" (X16) from the parameter "Gnostic emotional orientation" (X43).

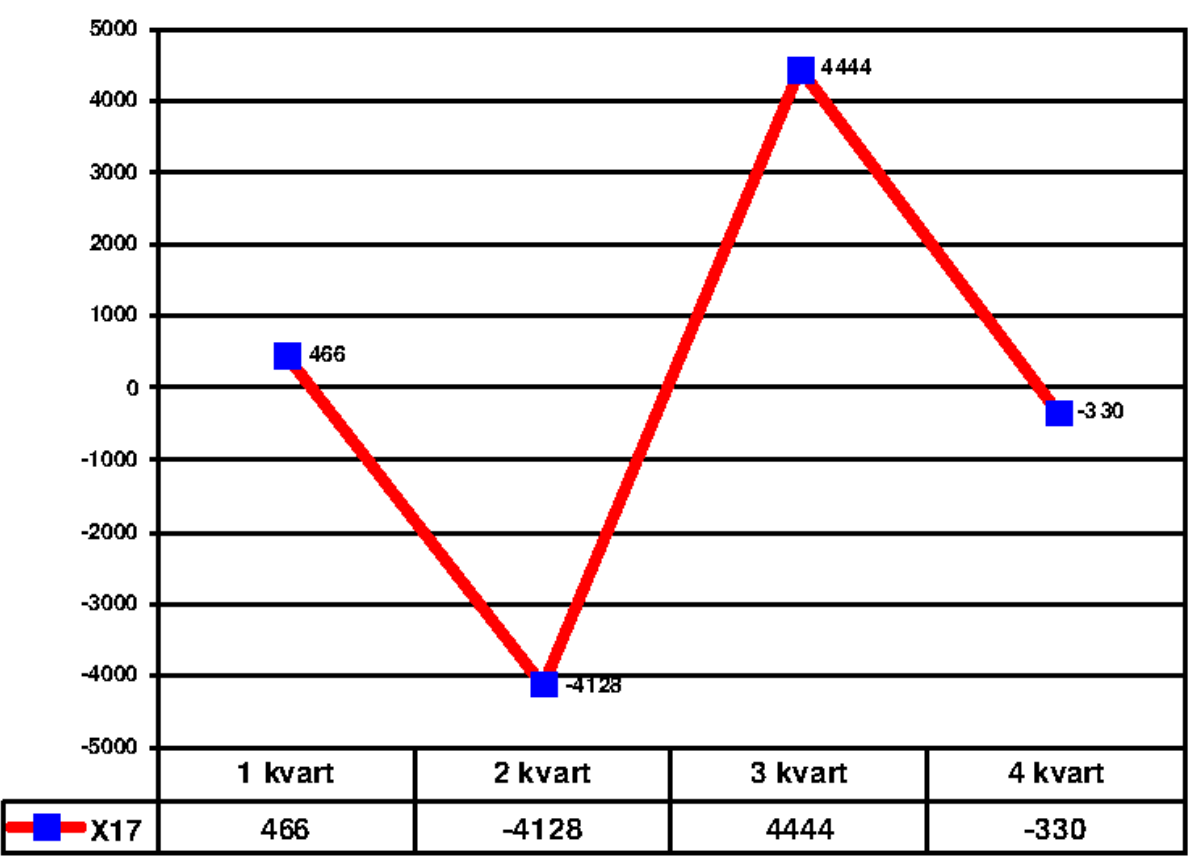

Figure 9. Dependence of the parameter "Positive sentiments about a child based on his dignity and achievements" (X17) from the parameter "Gnostic emotional orientation" (X43); 


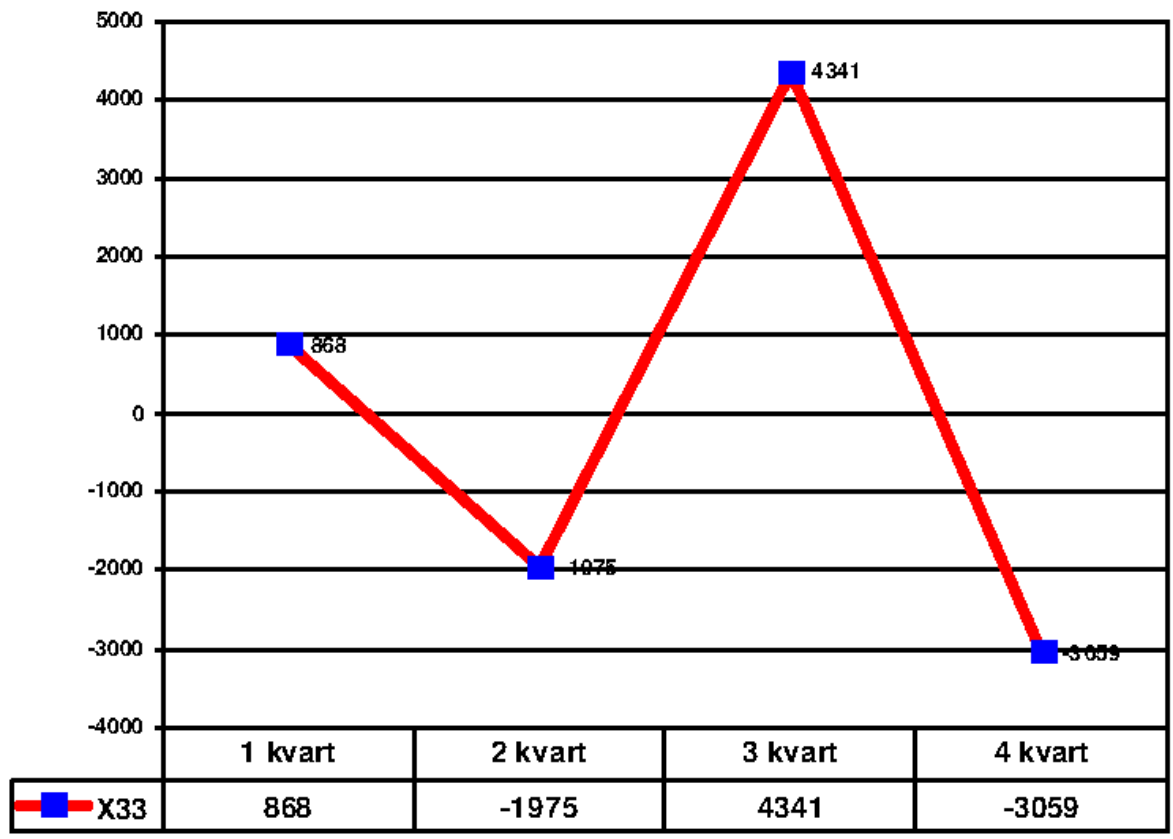

Figure 10. Dependence of the parameter "Asthenic sentiments" (X33) from the parameter "Pugnatic emotional orientation" (X47).

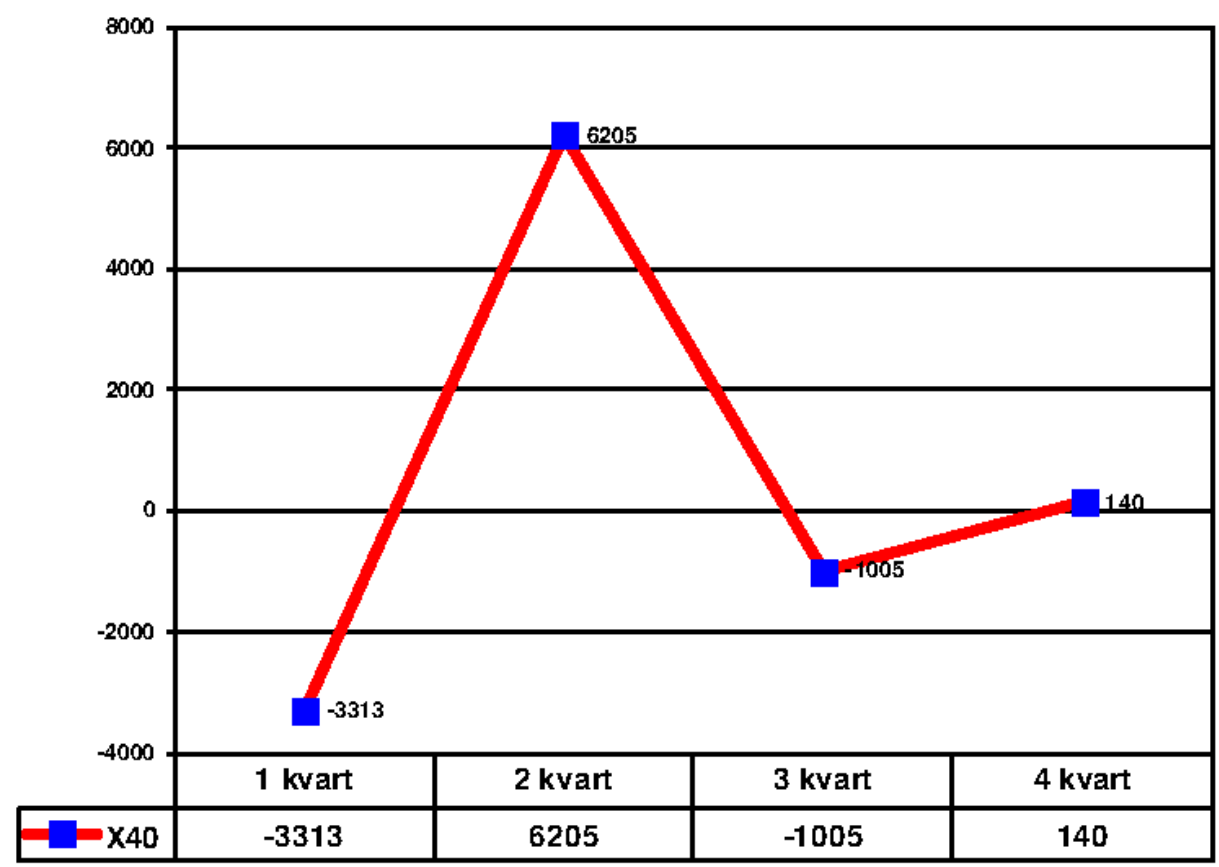

Figure 11. Dependence of the parameter "Gloric emotional orientation" (X40) from the parameter "General self-estimation of a child" (X48). 
The second selection of dependencies (Table 2) contains weaker simplest non-linear dependencies with a connection strength factor $0.6<\mathrm{SV}<0.7$, which simultaneously are also characterized by values of linear correlations close to zero from 0 to 0.16 , which is even lower than the threshold of the universally preferred "significant" correlation. The study under consideration has found 11 such dependencies.

TABLE II. INTERVALS OF RELATION COEFFICIENTS $0<\operatorname{ABS}(\mathrm{R})<=0.16 \quad 0.6<\mathrm{SV}<=0.7$

\begin{tabular}{|c|c|c|c|c|c|}
\hline & SV & $\mathbf{S V}^{\prime}$ & $\mathbf{R}$ & quarters & parameter \\
\hline 1 & 0.69 & 0.32 & -0.16 & X01 & X25 \\
\hline 2 & 0.61 & 0.19 & 0.07 & $\mathrm{X} 24$ & $\mathrm{X} 20$ \\
\hline 3 & 0.66 & 0.51 & -0.06 & X28 & X43 \\
\hline 4 & 0.60 & 0.19 & -0.10 & $\mathrm{X} 30$ & $\mathrm{X} 41$ \\
\hline 5 & 0.64 & 0.12 & 0.07 & X30 & $\mathrm{X} 50$ \\
\hline 6 & 0.66 & 0.20 & -0.03 & X31 & $\mathrm{X} 40$ \\
\hline 7 & 0.65 & 0.11 & 0.05 & X37 & X33 \\
\hline 8 & 0.66 & 0.16 & 0.03 & $\mathrm{X} 43$ & $\mathrm{X} 12$ \\
\hline 9 & 0.69 & 0.18 & 0.09 & X43 & X14 \\
\hline 10 & 0.63 & 0.10 & 0.13 & $\mathrm{X} 46$ & $\mathrm{X} 10$ \\
\hline 11 & 0.69 & 0.27 & 0.15 & $\mathrm{X} 47$ & X32 \\
\hline
\end{tabular}

TABLE III. INTERVALS OF RELATION COEFFICIENTS: $0.6<\operatorname{ABS}(\mathrm{R})<=1$

\begin{tabular}{|c|c|c|c|c|c|}
\hline & SV & SV $^{\prime}$ & $\mathbf{R}$ & quarters & parameter \\
\hline 1 & 0.92 & 0.94 & $\mathbf{0 . 6 5}$ & $\mathrm{X} 12$ & $\mathrm{X} 13$ \\
\hline 2 & 0.94 & 0.91 & $\mathbf{0 . 6 5}$ & $\mathrm{X} 12$ & $\mathrm{X} 14$ \\
\hline 3 & 0.93 & 0.92 & $\mathbf{0 . 6 5}$ & $\mathrm{X} 12$ & $\mathrm{X} 16$ \\
\hline 4 & 0.94 & 0.93 & $\mathbf{0 . 6 3}$ & $\mathrm{X} 12$ & $\mathrm{X} 17$ \\
\hline 5 & 0.94 & 0.92 & $\mathbf{0 . 6 2}$ & $\mathrm{X} 12$ & $\mathrm{X} 19$ \\
\hline 6 & 0.90 & 0.94 & $\mathbf{0 . 6 3}$ & $\mathrm{X} 12$ & $\mathrm{X} 20$ \\
\hline 7 & 0.94 & 0.93 & $\mathbf{0 . 6 4}$ & $\mathrm{X} 13$ & $\mathrm{X} 14$ \\
\hline 8 & 0.93 & 0.89 & $\mathbf{0 . 6 5}$ & $\mathrm{X} 13$ & $\mathrm{X} 15$ \\
\hline 9 & 0.89 & 0.91 & $\mathbf{0 . 6 4}$ & $\mathrm{X} 13$ & $\mathrm{X} 16$ \\
\hline 10 & 0.95 & 0.93 & $\mathbf{0 . 6 5}$ & $\mathrm{X} 13$ & $\mathrm{X} 17$ \\
\hline 11 & 0.92 & 0.88 & $\mathbf{0 . 6 6}$ & $\mathrm{X} 13$ & $\mathrm{X} 19$ \\
\hline 12 & 0.92 & 0.91 & $\mathbf{0 . 6 6}$ & $\mathrm{X} 14$ & $\mathrm{X} 15$ \\
\hline 13 & 0.93 & 0.93 & $\mathbf{0 . 6 5}$ & $\mathrm{X} 14$ & $\mathrm{X} 16$ \\
\hline 14 & 0.96 & 0.96 & $\mathbf{0 . 7 2}$ & $\mathrm{X} 14$ & $\mathrm{X} 17$ \\
\hline 15 & 0.90 & 0.91 & $\mathbf{0 . 6 3}$ & $\mathrm{X} 14$ & $\mathrm{X} 18$ \\
\hline 16 & 0.93 & 0.91 & $\mathbf{0 . 6 7}$ & $\mathrm{X} 14$ & $\mathrm{X} 19$ \\
\hline 17 & 0.90 & 0.83 & $\mathbf{0 . 6 7}$ & $\mathrm{X} 31$ & $\mathrm{X} 50$ \\
\hline
\end{tabular}

In conclusion, by way of a general comparison of the number of strong relations of different nature (linear, simplest non-linear) we supply a table containing really strong linear relations (correlation factor values exceed 0.6). Previously, such relations used to be considered as worth researchers' attention (for the selection under study covering 140 examinees) until the challenging time came when the complex psychological contents started to be simplified - via "significant" correlations - to linear models so that the pseudo-scientific information became common for the psychological science.

Seventeen (17) such dependencies were gathered, 16 of which are obviously linked by closely related parameters, presenting the grading scales of the method "Positive parental sentiments." It means that the results obtained allow us to speak about the mutual influence in the "parent-to-child" relationship, its emotional aspect, and parental sentiments, primarily those based on non-linear dependencies.

\section{CONCLUSION}

The important thing that must at the moment - in considering the matter - be the focus of the reader's attention when considering the above mentioned results, is the fact that the bulk of strong simplest non-linear relations in using the correlative analysis remain "invisible". They just do not exist and they must not be included in the traditional approach to describing the subject matter under investigation [2].

This is (in terms of M.M.Basimov) the 1st type of error. It can also be regarded as a serious blunder since no strong relations is discovered while it remains out of the investigator's view. It differs by virtue of its nature, i.e. it's of the simplest non-linear type. It means that in order to determine and interpret this we need other statistical methods (not only a correlative analysis) as well as other (synergetic) methodology corresponding to the complex nature of psychology and its phenomena. As for linear models, when even really strong relations are discovered and determined (with a correlation factor exceeding 0.6), they only vague describe the subject matter under study, regretfully distorting the true picture of the process and the procedure under study. It means that a practicing psychologist cannot use such results in his work.

In conclusion, let us list the "significant" linear correlations that this study has determined. In terms of absolute value from 0.5 to 0.6 we have got 23 correlations. In terms of an absolute value from 0.3 to 0.5 we have got 216 correlations.

Worth of special note is the number of very weak correlations. In terms of an absolute value from 0.16 to 0.3 we have got 351 very weak linear dependencies which despite such small values, in modern terms, are referred to the "significant" correlations. This means that they are worth of attention, which psychologists propose to consider as scientific results most of which are not scientifically interesting. Among them are, however, such that hide strong non-linear relations. For psychology these are mainly dependencies with a maximum and a minimum and such mistakes are dangerous given that they replace the model of 
the phenomenon under study and present the direct line model as an actual one that presents the simplest non-linear relation.

In a follow-up article, based on this study, we plan to consider mistakes in a situation when presented as "worth of attention" of the psychological community, is a very weak linear dependence in the form of dependencies which, on closer examination emerge as strong simplest non-linear dependencies (primarily with a maximum and a minimum). Such dangerous errors in terms of M.M. Basimov's notification are defined as type 2 errors.

\section{References}

[1] Basimov M.M. Dependencies in political studies (non-linearity and typical methodological errors) // The International Scientific and Practical Conference "Current Issues of Linguistics and Didactics: The Interdisciplinary Approach in Humanities and Social Sciences" (CILDIAH-2019) / SHS Web of Conferences. Volume 69. No. 00014. 2019.

[2] Basimov M.M. "Convenient" correlational errors in modern psychological science (mathematical aspect). The European Proceedings of Social \& Behavioural Sciences EpSBS, Vol. L, pp. 137-146, 2018.

[3] Basimova P.M. Commitment to Principles in Pedagogic Activity (nonlinear aspect). International Journal of Psychology, Vol. 51, S.1, pp. 789, 2016. DOI: $10.1002 /$ ijop. 12328.

[4] Basimova P.M. Competitiveness as the reason Impulsiveness in non-linear psychology (Five-Factor Personality Model). International Journal of Psychology, Vol. 51, S.1, pp. 903, 2016. DOI: 110.1002/ijop.12337.
[5] Danilov Yu.V. Nonlinearity. Introduction to Synergetics. http://spkurdyumov.ru/category/ introduction, 2016.

[6] Dodonov B.I. In the realm of emotions; Kiev, USSR, 1987.

[7] Ilinyh Y. Non-linear effects in interaction "child-parent". International Journal of Psychology, Vol. 47, S.1, pp. 261, 2012. DOI: 10.1080/00207594.2012.709096

[8] Ilinyh Y. Non-linear influence of severity on the lifemean orientations of the child. International Journal of Psychology, Vol. 47, S.1, pp. 261, 2012. DOI: $10.1080 / 00207594.2012 .709096$

[9] Knjazeva E.N.; Kurdyumov S.P. Bas of synergetrics. Synergetic Worldseeing; Moscow: KomKniga, RF, 2005.

[10] Krylov V.Yu. Methodological and idealized problems of mathematical psychology; Moscow: Yanus-K, RF, 2000.

[11] Kulikov L.V. Psychology of a person. Issues of psychological stability and psychological prophylactics: A teaching aid; St Petersburg: Piter, RF, 2004.

[12] Markovskaya I.M. Training the interaction between parents and children; SPb.: Rech, RF, 2002.

[13] Padurina E.A. Development of positive parental sentiments as a factor that corrects pre-school children's self-estimation. A thesis of a candidate of pedagogical sciences; Yekaterinburg, RF, 2008.

[14] Padurina E.A. Non-linear influence of the gnostic emotional orientations on parental feelings. International Journal of Psychology, Vol. 47, S.1, pp, 403, 2012. DOI: 10.1080/00207594.2012.709107.

[15] Shchur G.V. The methods of studying a child's notions about other people's attitude to him. Psychology of a person: a theory and an experiment; M., USSR, 1982.

[16] Zakharova E.I. Special features of the emotional aspect of the child-toparent interaction. A psychologist at kindergarten, No.1, pp. 3-29, 2002. 